\title{
The Effect of Various Media and Hormones via Suspension Culture on Secondary Metabolic Activities of (Cape Jasmine) Gardenia jasminoides Ellis
}

\author{
Reza Farzinebrahimi, ${ }^{1}$ Rosna Mat Taha, ${ }^{1}$ \\ Kamaludin Rashid, ${ }^{2}$ and Jamilah Syafawati Yaacob ${ }^{1}$ \\ ${ }^{1}$ Institute of Biological Sciences, Faculty of Science, University of Malaya, 50603 Kuala Lumpur, Malaysia \\ ${ }^{2}$ Biology Division, Centre for Foundation Studies in Science Building, University of Malaya, 50603 Kuala Lumpur, Malaysia \\ Correspondence should be addressed to Reza Farzinebrahimi; rfebrahimi@siswa.um.edu.my
}

Received 18 February 2014; Revised 7 April 2014; Accepted 14 April 2014; Published 21 May 2014

Academic Editor: João B. T. Rocha

Copyright (C) 2014 Reza Farzinebrahimi et al. This is an open access article distributed under the Creative Commons Attribution License, which permits unrestricted use, distribution, and reproduction in any medium, provided the original work is properly cited.

\begin{abstract}
The leaf of Gardenia jasminoides Ellis was used as explants and was cultured on MS and WPM media supplemented with various concentrations of NAA, IAA, 2,4-D, IBA, TDZ, and $\mathrm{Kn}$ ( 0 to $5 \mathrm{mg} \mathrm{L}^{-1}$ with 0.5 increment). After six months, the higher percentage of callus (100\%) and the best dry and fresh weight of callus were formed on WPM medium supplemented with 2,4-D and NAA (2.0$\left.3.0 \mathrm{mg} \mathrm{L}^{-1}\right)$ and this amount was decreased from $(84 \%)$ to $(69 \%)$ when this media supplemented with Kinetin and TDZ $\left(1 \mathrm{mg} \mathrm{L}^{-1}\right)$ respectively were used. Leaf segments cultured on WPM media added with $\mathrm{Kn}\left(1 \mathrm{mg} \mathrm{L}^{-1}\right)$ and TDZ $\left(2 \mathrm{mg} \mathrm{L}^{-1}\right)$ yielded the least amount of callus. It was found that WPM media added with IAA $\left(4.5-5.0 \mathrm{mg} \mathrm{L}^{-1}\right)$ were optimum for root induction from $G$. jasminoides plantlets. Antibacterial screening of leaf extracts (in vivo) showed no inhibitory effect against E. coli, $P$. aeruginosa, $S$. aureus, and B. cereus, in contrast to callus extracts from leaf cultures supplemented with NAA, which showed inhibition activity against E. coli and B. cereus. The callus extracts from leaf cultures grown on both MS and WPM media showed higher antioxidant and superoxide dismutase activities than leaf extracts.
\end{abstract}

\section{Introduction}

Gardenia jasminoides Ellis (Cape jasmine) belongs to Rubiaceae family and is native to the tropical and subtropical parts of Africa, Southern Asia, Australia, and Oceania. Gardenias are widely practiced as an ornamental flower in bouquets, as houseplants, and as outside plants. This plant is known as one of the most valuable plant species in traditional Chinese medicine and is considered highly effective as a haemostatic agent, drain fire, and is effective in treating injuries to the muscles, joints, and tendons [1]. The major components of Gardenia's fruits are iridoid glycosides, which can be converted into blue and red pigments. These crocetin derivatives are known for their colouring properties and their particular water-soluble behavior, in contrast to most plant families of carotenoids [2]. Carotenoids are thought equally as the main contributors to the antioxidant content of a particular plant and have been proven to yield beneficial pharmacological effects, such as preventing cardiovascular diseases [3].

Benzylaminopurine (BAP) gave high proliferation of the G. jasminoides compared to 6- $\gamma-\gamma$-[dimethylallylamino]purine (2iP) and kinetin [4], while using indole-3-butyric acid (IBA) in micro cuttings of G. jasminoides showed high percentages of root in vitro and ex vitro $[5,6]$. A combination of (TDZ) thidiazuron $\left(1.7 \mathrm{mg} \mathrm{L}^{-1}\right)$ with (IAA) indole-3-acetic acid $\left(1 \mathrm{mg} \mathrm{L}^{-1}\right)$ produced adventitious shoots on Gardenia explants [7]. Free radical scavenging activity has been reported from Gardenia jasminoides fruit extracts [8], as well as leaf extracts when grown in vivo and in vitro [9]. G. jasminoides also showed superoxide dismutaselike (SOD-like) activity [10]. The use of plant extracts and phytochemicals with antimicrobial contents can be of great 
significance and, recently, a number of studies have proven such efficiency. Izzo et al. [11] revealed the effect of phytochemical and the antimicrobial activity of anacardic acid which had an inhibitory effect on Staphylococcus aureus, Brevibacterium ammoniagenes, Streptococcus mutans, and Propionibacterium acnes. The present investigation aimed to study the antibacterial and antioxidant properties of $G$. jasminoides extracts obtained from leaves (in vivo) and callus (in vitro). For callus induction, leaf explants were cultured on MS and WPM media supplemented with various hormones at different concentrations. This study differs from previous work in the sense that callus or undifferentiated cells from in vitro or tissue culture system were used for comparison with intact tissue (in vivo).

\section{Materials and Methods}

2.1. Plant Materials. Six-month-old, young, and fresh leaves of G. jasminoides Ellis obtained from Serdang nursery (Malaysia) were surface sterilized by using mercuric chloride, Clorox, and ethanol [7, 9]. The sterilized explants were cut into $50 \times 50 \mathrm{~mm}$ segments and cultured onto $60 \mathrm{~mL}$ Murashige and Skoog (MS) medium [12] and WPM [13] in a sterile container, supplemented with various concentrations of auxins (NAA, IAA, IBA, and 2,4-D or 2,4dichlorophenoxyacetic acid), cytokinins (TDZ, Kn) (0.5$\left.5.0 \mathrm{mg} \mathrm{L}^{-1}\right)$, sucrose $(30 \mathrm{~g})$, and Gelrite $(5 \mathrm{~g})$. The $\mathrm{pH}$ was maintained on $5.7 \pm 2$ using HCL and $\mathrm{NaOH}(1 \mathrm{~N})$. The 3month callus formed in vitro was tested by double staining method [14] to obtain embryogenic cells. The embryogenic callus $(50 \mathrm{~g})$ was weighed out in laminar flow cabinet and was inoculated on the same hormone concentrations and media without agar and maintained on a horizontal shaker $(120 \mathrm{rpm})$ in a growth chamber at $24^{\circ} \mathrm{C}$, with 16 hours light and 8 hours dark conditions.

The callus aggregate was used as samples for subsequent analysis after 6 months of culture. Young leaves of intact $G$. jasminoides ( $60 \mathrm{~g}$ ) were also used as a comparison (in vivo).

2.2. Extract Preparation. In vitro samples (6-month-old callus) and in vivo samples (leaves of intact G. jasminoides) were dried in an incubator at $40^{\circ} \mathrm{C}$ and ground to produce fine homogenous powder by using an electric blender. The ground powders $(3 \mathrm{~g})$ of both samples were soaked in 5\% Tween $20(40 \mathrm{~mL})$ at room temperature and were filtered through Whatman No. 1 filter paper (Whatman International, England).

2.3. Antioxidant Activity Assay. Superoxide dismutase (SOD) determination kit (19160), ascorbic acid (A4544) from SigmaAldrich (St. Louis, Mo), and tert-butylated hydroxytoluene (34750) from Fluka (Spain) were purchased and used for this part of the study. Plant extracts $(20 \mu \mathrm{L})$ with a concentration of $10 \mathrm{~g} \mathrm{~L}^{-1}$ were added to $200 \mu \mathrm{L}$ of the kit working solution. The mixture, after a gentle shaking, was incubated at $37^{\circ} \mathrm{C}$ for $20 \mathrm{~min}$ after adding $20 \mu \mathrm{L}$ of the kit enzyme working solution. The absorbance of the mixtures was measured at $450 \mathrm{~nm}$ using a microplate reader (BIO-RAD Model 550,
USA) and the SOD activity was calculated based on the following equation [15]. Ascorbic acid $\left(1 \mathrm{gL}^{-1}\right)$ and BHT or tert-butylated hydroxytoluene $\left(1 \mathrm{~g} \mathrm{~L}^{-1}\right)$ were employed as the positive controls in this study:

$$
\begin{aligned}
& \text { Inhibition\% (SOD activity) } \\
& \qquad=\frac{\left(\text { blank }_{1}-\text { blank }_{2}\right)-\left(\text { sample }_{\mathrm{A}}-\text { blank }_{\text {sample }_{\mathrm{A}}}\right)}{\left(\text { blank }_{1}-\text { blank }_{2}\right)} \times 100,
\end{aligned}
$$

where blank ${ }_{1}=$ blank of mixture working solution + enzyme working solution + double distilled water, blank $k_{2}=$ blank of mixture plant extract + working solution + dilution buffer + double distilled water, and blank (sample $\left._{\mathrm{A}}\right)=$ blank of mixture plant extract + working solution + dilution buffer.

2.4. Antibacterial Activity Assay. The antibacterial potential of G. jasminoides was studied based on the paper disc diffusion method $[15,16]$. Two gram-negative pathogenic bacteria (Escherichia coli and Pseudomonas aeruginosa) and two gram-positive bacteria (Bacillus cereus and Staphylococcus aureus) were obtained from Microbiology Division of Institute of Biological Sciences and grown in a nutrient broth medium to yield a final concentration of 107 colony forming unit (CFU) per $\mathrm{mL}^{-1}$. The test bacteria $(0.1 \mathrm{~mL})$ were streaked on Mueller Hinton medium (MH) plates using sterile cotton swab. Sterilized filter paper discs were soaked in extracts $\left(100 \mathrm{~g} \mathrm{~L}^{-1}\right)$ and then placed at the center of test bacteria plates. The plates were incubated for $24 \mathrm{~h}$ and the diameters of the inhibition zones were measured. Tetracycline disc $(30 \mu \mathrm{g})$ and PBS were used as the positive and negative controls, respectively.

2.5. Statistical Analysis. Experiments were designed based on complete randomized design (CRD) with six replicates. Data analysis was carried out using SPSS version 21 and analysis of variance (ANOVA) was carried out. The means were separated via Duncan's multiple comparison test (DMCT) and $P<0.05$ was considered to indicate statistical significance.

\section{Results}

3.1. Induction of Callogenesis from Leaf Explants of Gardenia jasminoides. Initiation of callus was observed from the young leaf explants after three weeks of culture on the MS and WPM medium supplemented with different plant growth regulators such as NAA and IAA. The friable, greenish, and yellowish callus were formed on the media supplemented with TDZ $\left(1\right.$ and $\left.1.5 \mathrm{mg} \mathrm{L}^{-1}\right)$ and IBA $\left(1 \mathrm{mg} \mathrm{L}^{-1}\right)$. The results of double staining test showed that embryogenic cells were formed on callus grown with various auxin and nonembryogenic callus formed on MS supplemented with TDZ and Kn.

Callus formation was observed after as early as three to five weeks of induction on both MS and WPM media supplemented with auxins and cytokinins. MS media supplemented with IBA and NAA $\left(2.0-3.0 \mathrm{mg} \mathrm{L}^{-1}\right)$ as well as IAA (2.5$3.0 \mathrm{mg} \mathrm{L}^{-1}$ ) also showed $100 \%$ callus formation. However, 


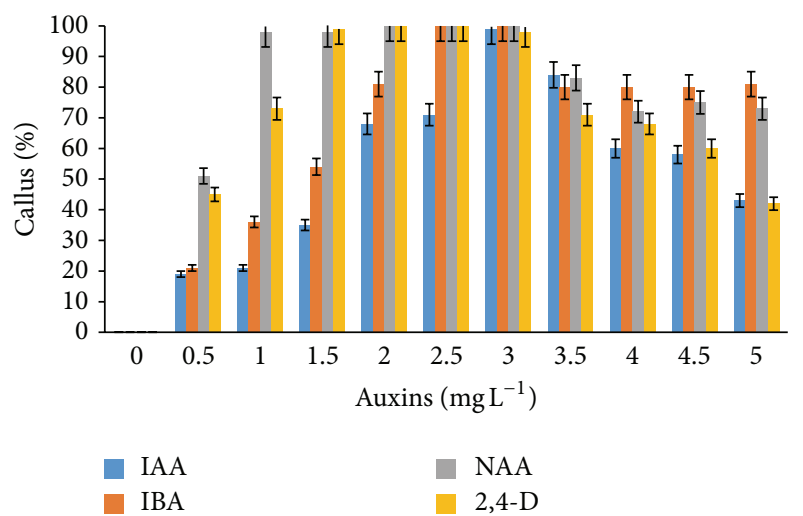

FIgUre 1: Percentage of callus formation from leaf explants of $G$. jasminoides cultured on MS media supplemented with different types of auxin at various concentrations after 6 months of culture $(P<0.05, n=6)$.

the addition of 2,4-D (2.5-3.0 $\left.\mathrm{mg} \mathrm{L}^{-1}\right)$ to the MS media only produced $90 \%$ callus formation (Figure 1). Extremely high callus percentage (100\%) was observed from WPM media supplemented with NAA and 2,4-D (2.0-3.0 $\left.\mathrm{mg} \mathrm{L}^{-1}\right)$ alone and IBA (2.5-3.0 $\mathrm{mg} \mathrm{L}^{-1}$ ) (Figure 2). Lower portions of callus growth (84\% and 69\%) were observed when WPM media were supplemented with kinetin and TDZ $\left(1.0 \mathrm{mg} \mathrm{L}^{-1}\right)$, respectively (Figure 3). However, the addition of kinetin and TDZ to WPM was found to be ineffective as shown by the striking decrease in callus formation to $58 \%$ and $25 \%$ when kinetin $\left(1.0 \mathrm{mg} \mathrm{L}^{-1}\right)$ and TDZ $\left(2.0 \mathrm{mg} \mathrm{L}^{-1}\right)$ were added alone, respectively (Figure 4). In contrast, adding kinetin and TDZ to MS media was found to be beneficial and helped boost callogenesis in G. jasminoides. It was found that both media supplemented with 2,4-D and kinetin affected the callus weight. The type of media also influenced the yield of callus when supplemented with similar plant hormones. It was perceived that the addition of 2,4-D $\left(3.0 \mathrm{mg} \mathrm{L}^{-1}\right)$ and kinetin $\left(5.0 \mathrm{mg} \mathrm{L}^{-1}\right.$ ) to the WPM media yielded $34.23 \mathrm{~g}$ and $3.39 \mathrm{~g}$ of fresh and dry weight of callus, respectively. In contrast, MS media supplemented with 2,4-D $\left(2.5 \mathrm{mg} \mathrm{L}^{-1}\right)$ and kinetin $\left(4.0 \mathrm{mg} \mathrm{L}^{-1}\right)$ only generated $30.04 \mathrm{~g}$ and $3.78 \mathrm{~g}$ fresh and dry weight of callus, respectively (Figure 5).

Rooting induction and root elongation from in vitro regenerates of $G$. jasminoides were also examined in the present investigation. The addition of auxins to both MS and WPM media demonstrated different results. Rooting was observed from leaf explants cultured on both MS and WPM media after the fifth week. In WPM medium, the use of NAA $\left(1.5-2.0 \mathrm{mg} \mathrm{L}^{-1}\right)$ exhibited excellent root growth of 14.8 and $13.4 \mathrm{~cm}$, respectively (Figure 6). Addition of 2,4-D (4.5$5.0 \mathrm{mg} \mathrm{L}^{-1}$ ) and NAA (2.0-3.0 $\left.\mathrm{mg} \mathrm{L}^{-1}\right)$ to WPM media also promoted root growth (Figure 7).

3.2. Screening Antibacterial Activity of the Leaf and Callus Extracts in Gardenia jasminoides. Antibacterial activity was determined by measuring the zone of inhibition depicted by leaf and callus extracts of G. jasminoides extracts on

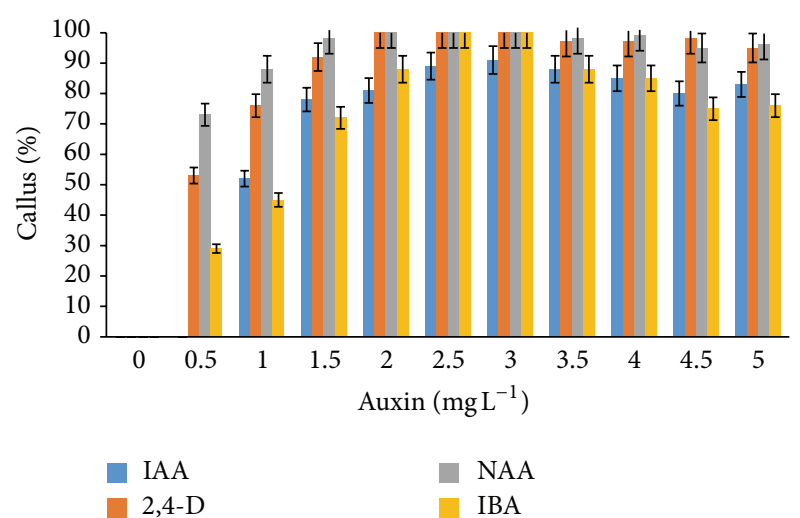

FIgURE 2: Percentage of callus formation from leaf explants of $G$. jasminoides cultured in WPM medium supplemented with different types of auxin at various concentrations after 6 months of culture $(P<0.05, n=6)$.

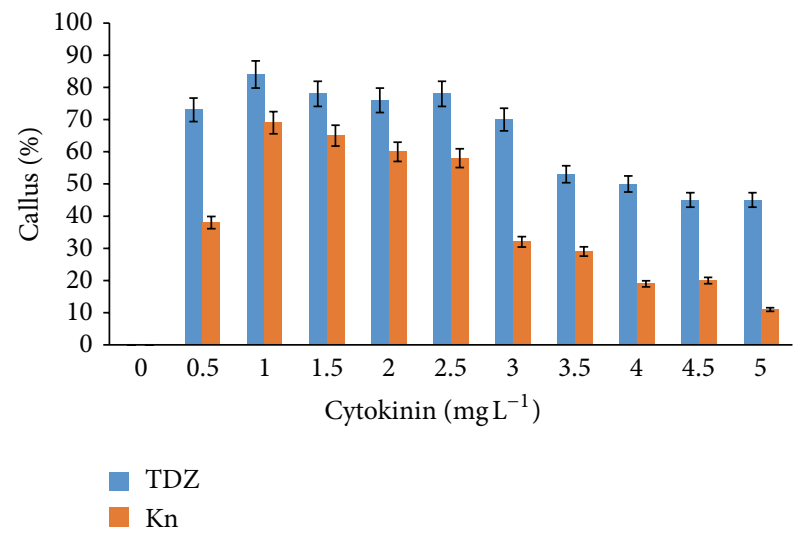

FIgURE 3: Percentage of callus formation from leaf explants of $G$. jasminoides cultured on MS media supplemented with different types of cytokinin at various concentrations after 6 months of culture $(P<0.05, n=6)$.

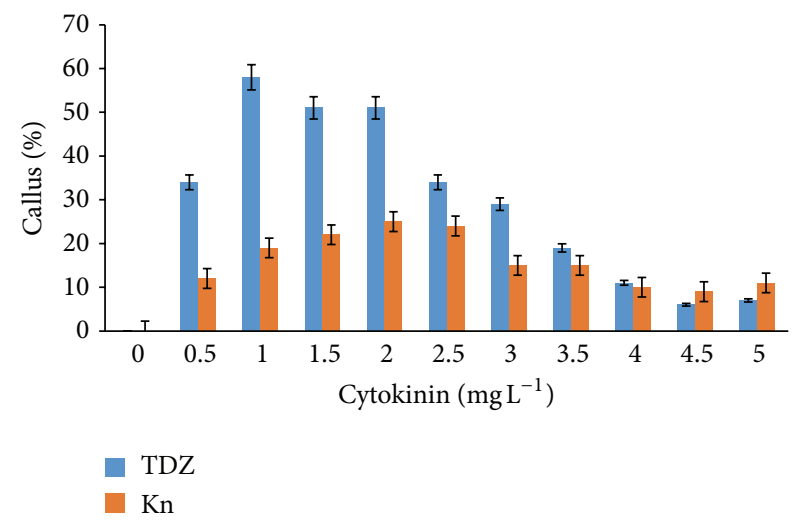

FIGURE 4: Percentage of callus formation from leaf explants of $G$. jasminoides cultured in WPM medium supplemented with different types of cytokinin at various concentrations after 6 months of culture $(P<0.05, n=6)$. 


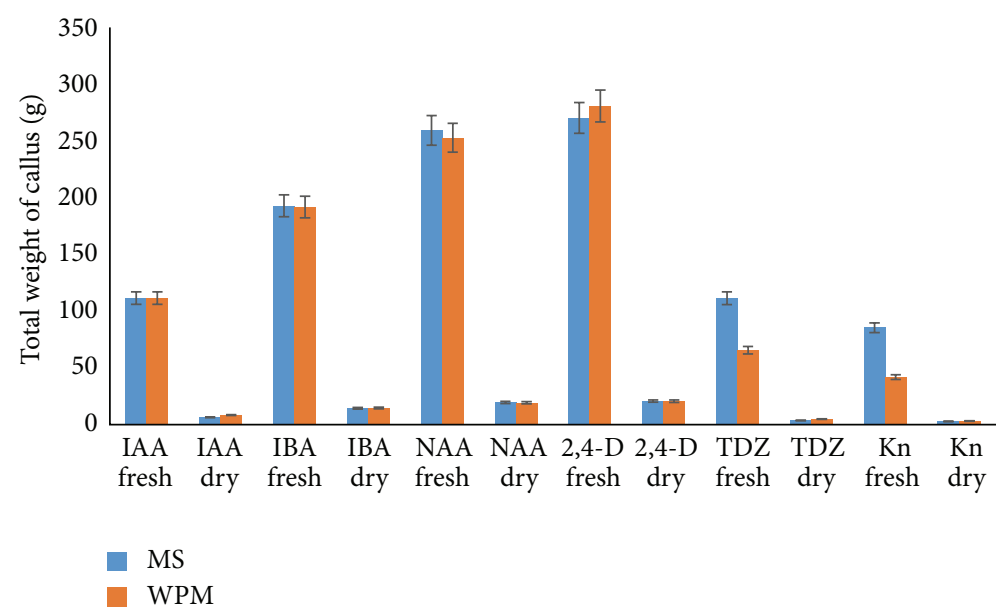

FIGURE 5: Mean comparison between dry and fresh weight of callus obtained from leaf explants of G. jasminoides cultured on WPM and MS media supplemented with various hormones $(P<0.05, n=6)$.

TABLE 1: Inhibition zone exhibited by leaf extracts $\left(100 \mathrm{~g} \mathrm{~L}^{-1}\right)$ in vivo grown and callus extracts (in vitro) from leaf cultures of Gardenia jasminoides against four pathogenic bacteria $(n=5)$.

\begin{tabular}{lccc}
\hline Bacteria & In vivo (leaf extracts) & $\begin{array}{c}\text { In vitro (callus extracts from MS and WPM media } \\
\text { supplemented with NAA) }\end{array}$ & Tetracycline $(30 \mu \mathrm{g})$ \\
\hline Escherichia coli & - & + & $39 \pm 3.04$ \\
Staphylococcus aureus & - & - & $21 \pm 1.98$ \\
Pseudomonas aeruginosa & - & - & $11 \pm 1.99$ \\
Bacillus cereus & - & + & $41 \pm 3$ \\
\hline
\end{tabular}

-: no activity.

+ : presence of activity.

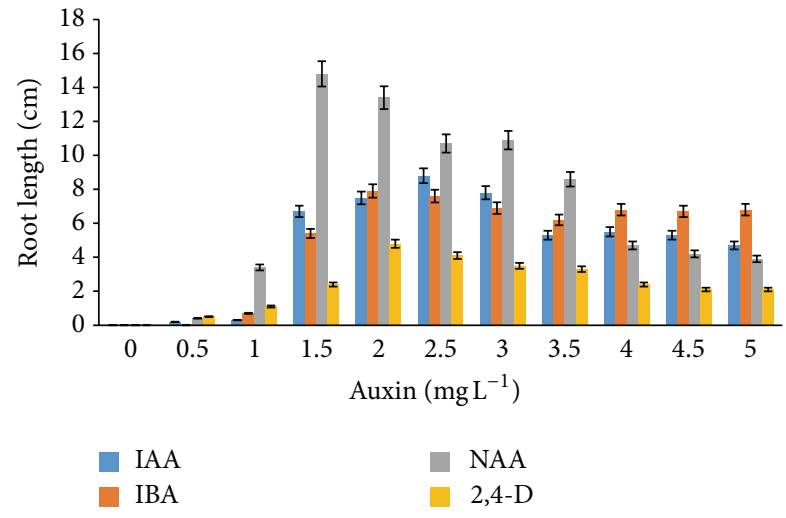

FIGURE 6: Root length of G. jasminoides when cultured on MS medium supplemented with various auxins after 6 months of culture $(P<0.05, n=6)$.

Escherichia coli, Staphylococcus aureus, Pseudomonas aeruginosa, and Bacillus cereus. It was found that leaf extracts of G. jasminoides grown in vivo showed no inhibitory activity against all four types of bacteria (Table 1). In contrast, callus extracts grown on both MS and WPM media supplemented with NAA showed inhibitory effects on Escherichia coli and

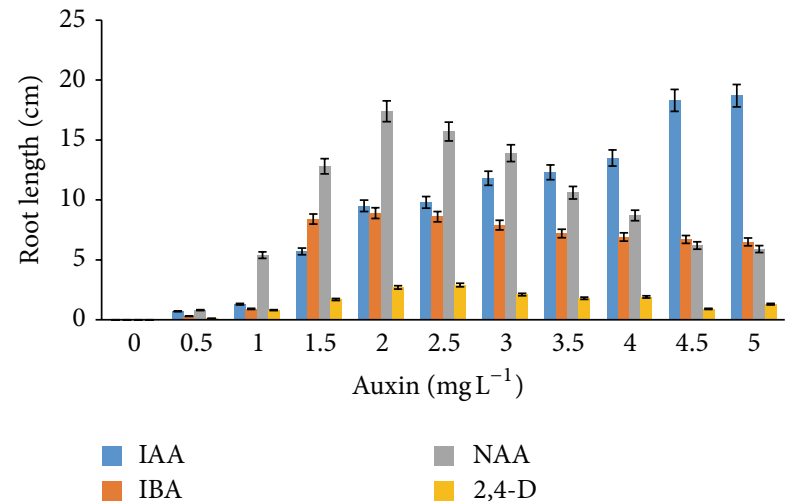

FIGURE 7: Root length of G. jasminoides when cultured in WPM medium supplemented with various auxins after 6 months of culture $(P<0.05, n=6)$.

Bacillus cereus (Table 1). However, no inhibitory influence was observed by G. jasminoides callus extracts against Staphylococcus aureus and Pseudomonas aeruginosa (Table 1).

3.3. Screening for Antioxidant and Superoxide Dismutase Activities. Antioxidant including superoxide dismutase 


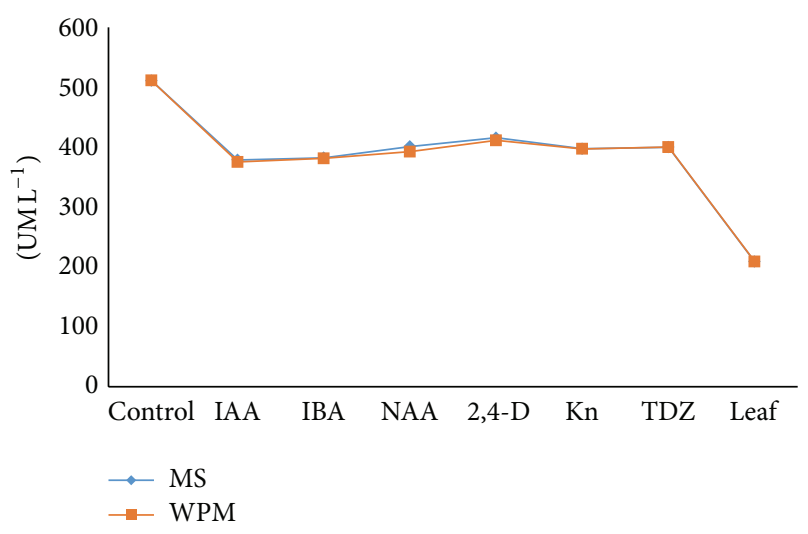

FIGURE 8: A comparison of superoxide dismutase (SOD) activity between leaf extracts of in vivo grown plant and callus extracts from leaf cultures of G. jasminoides grown on different media (MS and WPM) supplemented with various plant hormones $(P<0.05, n=$ $5)$.

activities was evaluated via superoxide dismutase (SOD) kit. Analysis of results showed that callus extracts of G. jasminoides $\left(\sim 30 \mathrm{U} \mathrm{mL}^{-1}\right)$ had significantly higher superoxide dismutase activities compared to leaf extracts of in vivo $\left(10 \mathrm{U} \mathrm{mL}^{-1}\right)$ grown G. jasminoides (Figure 8). The addition of various plant hormones to the callus regeneration media revealed no significant effect in influencing the antioxidant and superoxide dismutase activities expressed by specific callus extracts (Figure 8). These data recommend that plant hormones performed a role in modifying antioxidant and superoxide dismutase properties of a plant, although not significant in G. jasminoides. The present study also proves that antioxidant and superoxide dismutase potential of a plant (such as Gardenia jasminoides Ellis) can be improved by means of tissue culture, particularly via callogenesis.

\section{Discussion}

In the current work, callus was obtained from MS and WPM media supplemented with all different kinds of hormones. However, embryonic callus was only formed on the media that were supplemented with various types of auxin. The greenish and yellowish callus observed on both media supplemented with TDZ and IBA were similar to those reported by Eeckhaut et al. [17] on this family.

Using leaf segments from G. jasminoides plants germinated in vitro, friable calli were induced by the presence of cytokinins. This coincides with results obtained by AlJuboory et al. [7] who reported shoot induction from leaf explants in MS media supplemented with TDZ and Kn $\left(0.5 \mathrm{mg} \mathrm{L}^{-1}\right)$. In this investigation, no shoot formation was observed from leaf cultures of G. jasminoides when TDZ and kinetin were added to the growth media, contrary to the findings by Duhoky and Rasheed [18] and Sayd et al. [9] who reported the formation of shoots from leaf cultures of this species.

The present study was conducted to mass propagate $G$. jasminoides Ellis via in vitro techniques by utilizing different growth media and various plant hormones and it also aimed to manipulate and evaluate antibacterial, antioxidant, and superoxide dismutase properties of G. jasminoides via callogenesis. Based on the results obtained from this investigation, it was observed that callus can be readily induced from both types of media (MS and WPM), simply by increasing the plant hormones which may exhibit different effects when supplemented to different growth media. Concentration of plant hormones was similarly used to affect the percentage of callus formation.

2,4-D has been the best option of auxin and has been widely utilized to promote callus induction in many plant species. However, the present study revealed that WPM media supplemented with this hormone produced an inadequate performance in callogenesis of G. jasminoides plants as shown by the low values of both fresh and dry weights of callus obtained. Abdel-Rahim et al. [19] and Sayd et al. [9] reported the effect of 2,4-D when added to MS media.

The data analyzed showed no significant differences in callus formation between various auxins on WPM media; in contrast, MS media showed significant differences between IAA to other auxins. In addition, kinetin and TDZ supplemented to MS media showed statistically significant differences compared to WPM media. There was little difference between these two hormones on WPM media. More variations of callus formation calculated on WPM supplemented with TDZ compare to Kn.

MS media have been widely utilized in tissue culture of Cape jasmine $[7,9,18]$; WPM media were found to be a preferable choice, especially for callogenesis, due to its different nutrient, calcium, and phosphate content [20].

This study also investigates the antibacterial properties of G. jasminoides plant extracts, especially from leaf extracts of in vivo grown plants as well as callus extracts of this species. In general, plant extracts are usually more active and exhibited higher inhibitory influence against gram-positive (S. aureus) bacteria compared to gram-negative bacteria ( $S$. typhimurium) [21]. Abu-Shanab et al. [22] reported higher resistance of gram-negative bacteria to plant extracts compared to gram-positive bacteria. This is probably due to the different permeability of the bacterial cell wall or membrane accumulation process [23]. In the present study, experimental data demonstrated that leaf extracts of in vivo grown $G$. jasminoides showed no inhibition against four tested bacteria. However, callus extracts obtained from leaf cultures grown on both MS and WPM media supplemented with NAA revealed inhibitory impression against one gram-negative and one gram-positive bacteria, specifically Escherichia coli and Bacillus cereus. These results are in agreement with the previous findings by Wei et al. [23], Abdul Manaf [24], Møretrø et al. [25], Ragasa et al. [26], and Wei et al. [27]. Data analysis also recommended that antibacterial properties of a plant (such as Gardenia jasminoides) could be manipulated to be improved through tissue culture procedures, especially via callogenesis. This might be due to the use of plant hormones that may modify or have an effect on the synthesis of bioactive compounds of G. jasminoides.

Moreover, antioxidant and superoxide dismutase activities were also studied in the present investigation. Superoxide 
dismutase (SOD) is an enzyme that catalyzes the dismutation of superoxide into oxygen and hydrogen peroxide. As such, SOD performed an essential role in the cell's antioxidant defense against oxygen. SOD is also a portion of the defense system in aerobic organisms against oxidative stress, especially in catalysis of superoxide anion $\left(\mathrm{O}_{2}\right)$ and hydrogen peroxide, which are reduced to water via hydrogen peroxide scavenging enzyme (catalase). Hence, catalase and SOD are considered to limit the accumulation of reactive oxygen. SOD kit-like enzymes have been used by Miszalski et al. [28], Dos Santos et al. [29], and Shilpashree and Kumar [30] to investigate antioxidant activities exhibited by different species. Antioxidant properties had also been reported from $G$. jasminoides fruit extracts $[27,31-33]$. Up to our knowledge, the present investigation reports for the first time the manipulation and enhancement of antioxidant properties of G. jasminoides through tissue culture (callogenesis) by using plant hormones such as IBA, TDZ, and kinetin to enhance growth and promote the synthesis of bioactive compounds of $G$. jasminoides. The results obtained in the present investigation proved that Gardenia jasminoides is a rich source of antioxidants, and the use of plant hormones can improve superoxide dismutase potential and increase antibacterial properties of this plant against Escherichia coli and Bacillus cereus.

WPM medium was observed to be a better medium for callus formation from G. jasminoides leaf explants compared to MS medium, possibly due to its different nutrient (calcium or phosphate) content. G. jasminoides was discovered to be rich in antioxidants and its antioxidant properties are improved in vitro via the utilization of plant hormones. Antioxidant properties exhibited by callus extracts of these species showed statistical difference compared to leaf extracts from in vivo grown plant. The callus extracts obtained from growth media supplemented with NAA showed antibacterial activity against Escherichia coli and Bacillus cereus, while leaf extracts from in vivo grown G. jasminoides showed no inhibitory effect against all tested bacteria. Alternative growth media can also be utilized for micropropagation of G. jasminoides such as SH, B5, and LS media. Antitumor and other biological activity tests of $G$. jasminoides extracts can also be investigated in the near future.

\section{Conflict of Interests}

The authors declare that there is no conflict of interests regarding the publication of this paper.

\section{Acknowledgment}

The authors would like to thank the University of Malaya for the facilities and financial assistance provided (IPPP Grant no. PG091-2013A) to carry out the research.

\section{References}

[1] S. Dharmananda, Gardenia: Key Herb for Dispelling Dampness and Heat via the Triple Burner, ITM, 2003.
[2] M. R. Van-Calsteren, M. C. Bissonnette, F. Cormier et al., "Spectroscopic characterization of crocetin derivatives from Crocus sativus and Gardenia jasminoides," Journal of Agricultural and Food Chemistry, vol. 45, pp. 1055-1061, 1997.

[3] S.-Y. He, Z.-Y. Qian, F.-T. Tang, N. Wen, G.-L. Xu, and L. Sheng, "Effect of crocin on experimental atherosclerosis in quails and its mechanisms," Life Sciences, vol. 77, no. 8, pp. 907-921, 2005.

[4] T.-H. Tseng, C.-Y. Chu, J.-M. Huang, S.-J. Shiow, and C.J. Wang, "Crocetin protects against oxidative damage in rat primary hepatocytes," Cancer Letters, vol. 97, no. 1, pp. 61-67, 1995.

[5] S. P. Hatzilazarou, T. D. Syros, T. A. Yupsanis, A. M. Bosabalidis, and A. S. Economou, "Peroxidases, lignin and anatomy during in vitro and ex vitro rooting of gardenia (Gardenia jasminoides Ellis) microshoots," Journal of Plant Physiology, vol. 163, no. 8, pp. 827-836, 2006.

[6] C. A. Pontikis, "In vitro propagation of Gardenia jasminoides," Plant Propagator, vol. 29, pp. 13-14, 1983.

[7] K. H. Al-Juboory, R. M. Skirvin, and D. J. Williams, "Callus induction and adventitious shoot regeneration of gardenia (Gardenia jasminoides Ellis) leaf explants," Scientia Horticulturae, vol. 72, no. 3-4, pp. 171-178, 1998.

[8] Y. Chen, H. Zhang, Y.-X. Li et al., "Crocin and geniposide profiles and radical scavenging activity of gardenia fruits (Gardenia jasminoides Ellis) from different cultivars and at the various stages of maturation," Fitoterapia, vol. 81, no. 4, pp. 269-273, 2010.

[9] S. S. Sayd, H. A. A. Taie, and L. S. Taha, "Micropropagation, antioxidant activity, total phenolics and flavonoids content of Gardenia jasminoides Ellis as affected by growth regulators," International Journal Academic Research, vol. 2, pp. 184-191, 2010.

[10] T. Debnath, P.-J. Park, N. C. Deb Nath, N. B. Samad, H. W. Park, and B. O. Lim, "Antioxidant activity of Gardenia jasminoides Ellis fruit extracts," Food Chemistry, vol. 128, no. 3, pp. 697-703, 2011.

[11] A. A. Izzo, G. Di Carlo, D. Biscardi et al., "Biological screening of italian medicinal plants for antibacterial activity," Phytotherapy Research, vol. 9, no. 4, pp. 281-286, 1995.

[12] T. Murashige and F. Skoog, "A revised medium for rapid growth and bioassays with tobacco cultures," Physiologia Plantarum, vol. 15, pp. 473-497, 1962.

[13] G. Lloyd and B. Mc Cown, "Commercially feasible micropropagation of mountain laurel, Kalmia latifolia, by use of shoot tip culture," Combined Proceedings, International Plant Propagators' Society, vol. 30, pp. 421-427, 1980.

[14] P. K. Gupta and D. J. Durzan, "Biotechnology of somatic polyembryogenesis and plantlet regeneration in loblolly pine," Bio/Technology, vol. 5, no. 2, pp. 147-151, 1987.

[15] A. Khorasani, W. Sani, K. Philip, R. M. Taha, and A. Rafat, "Antioxidant and antibacterial activities of ethanolic extracts of Asparagus officinalis cv. Mary Washington: Comparison of in vivo and in vitro grown plant bioactivities," African Journal of Biotechnology, vol. 9, no. 49, pp. 8460-8466, 2010.

[16] H. Y. Kil, E. S. Seong, B. K. Ghimire et al., "Antioxidant and antimicrobial activities of crude sorghum extract," Food Chemistry, vol. 115, no. 4, pp. 1234-1239, 2009.

[17] T. Eeckhaut, K. Janssens, E. D. Keyser, and J. D. Riek, "Micropropagation of rhododendron," in Protocols For in Vitro Propagation of Ornamental Plants, Methods in Molecular Biology, S. M. Jain and S. J. Ochatt, Eds., pp. 141-152, Humana Press, Helsinki, Finland, 2010. 
[18] M. Duhoky and K. Rasheed, "Effect of different concentrations of kinetin and NAA on micropropagation of Gardenia jasminoides," Journal of Zankoy Sulaimani A, vol. 13, pp. 103-120, 2010.

[19] E. Abdel-Rahim, O. M. Abdel-Fattah, M. I. Kabasse, H. ElShemy, and M. B. El-?Samei, "Growth of date palm callus as affected by growth regulators, sugars as carbon source and amino acids as organic nitrogen source," Arab Journal of Biotechology, vol. 1, pp. 99-106, 1998.

[20] M. Behbahani, M. Shanehsazzadeh, and M. J. Hessami, "Optimization of callus and cell suspension cultures of Barringtonia racemosa (Lecythidaceae family) for lycopene production," Scientia Agricola, vol. 68, no. 1, pp. 69-76, 2011.

[21] D. F. Basri and S. H. Fan, "The potential of aqueous and acetone extracts of galls of Quercus infectoria as antibacterial agents," Indian Journal of Pharmacology, vol. 37, no. 1, pp. 26-29, 2005.

[22] B. Abu-Shanab, G. Adwan, D. Abu-Safiya, K. Adwan, and M. Abu-Shanab, "Antibacterial ýactivity of Rhus coriaria. L extracts growing in Palestine," Journal of the Islamic University of Gaza, vol. 13, pp. 147-153, 2005.

[23] L. S. Wei, N. Musa, C. T. Sengm, W. Wee, and N. A. M. Shazili, "Antimicrobial properties of tropical plants against 12 pathogenic bacteria isolated from aquatic organisms," African Journal of Biotechnology, vol. 7, no. 13, pp. 2275-2278, 2008.

[24] A. Abdul Manaf, "Antimicrobial activity of selected Malaysian plants," Pertanika Journal of Tropical Agricultural Science, vol. 18, pp. 57-61, 1995.

[25] T. Møretrø, T. Sonerud, E. Mangelrød, and S. Langsrud, "Evaluation of the antibacterial effect of a triclosan-containing floor used in the food industry," Journal of Food Protection, vol. 69, no. 3, pp. 627-633, 2006.

[26] C. Y. Ragasa, L. E. N. Pimenta, and J. A. Rideout, "Iridoids from Gardenia jasminoides," Natural Product Research, vol. 21, no. 12, pp. 1078-1084, 2007.

[27] S. Wei, Z. Li, L. Jian-Tao, L. Hua, W. Xiao-Hua, and L. Dan, "Antioxidant Activity of Total Saponins from Gardenia jasminoides Fruits," Food Science, vol. 30, pp. 75-77, 2009.

[28] Z. Miszalski, A. Kornas, K. Gawronska et al., "Superoxide dismutase activity in C3 and C3/CAM intermediate species of Clusia," Biologia Plantarum, vol. 51, no. 1, pp. 86-92, 2007.

[29] W. G. Dos Santos, I. Pacheco, M.-Y. Liu, M. Teixeira, A. V. Xavier, and J. LeGall, "Purification and characterization of an iron superoxide dismutase and a catalase from the sulfatereducing bacterium Desulfovibrio gigas," Journal of Bacteriology, vol. 182, no. 3, pp. 796-804, 2000.

[30] R. Shilpashree and S. B. Kumar, "A study on anti-stress property of Nardostachys jatamamsi on stress induced Drosophila melanogaster," Journal of Stress Physiology and Biochemistry, vol. 7, pp. 159-164, 2011.

[31] Y. Fan, Z. Ge, and A. Luo, "In vitro antioxidant activity of polysaccharide from Gardenia jasminoides Ellis," Journal of Medicinal Plant Research, vol. 5, no. 14, pp. 2963-2968, 2011.

[32] S.-J. Lee, P.-S. Oh, J.-H. Ko, K. Lim, and K.-T. Lim, "Glycoprotein isolated from Gardenia jasminoides Ellis has a scavenging activity against oxygen radicals and inhibits the oxygen radicalinduced protein kinase $\mathrm{C}$ alpha and nuclear factor-kappa $\mathrm{B}$ in NIH/3T3 cells," Environmental Toxicology and Pharmacology, vol. 21, no. 1, pp. 8-21, 2006.

[33] T. Q. Pham, F. Cormier, E. Farnworth, H. Van Tong, and M.-R. Van Calsteren, "Antioxidant properties of crocin from Gardenia jasminoides Ellis and study of the reactions of crocin with linoleic acid and crocin with oxygen," Journal of Agricultural and Food Chemistry, vol. 48, no. 5, pp. 1455-1461, 2000. 

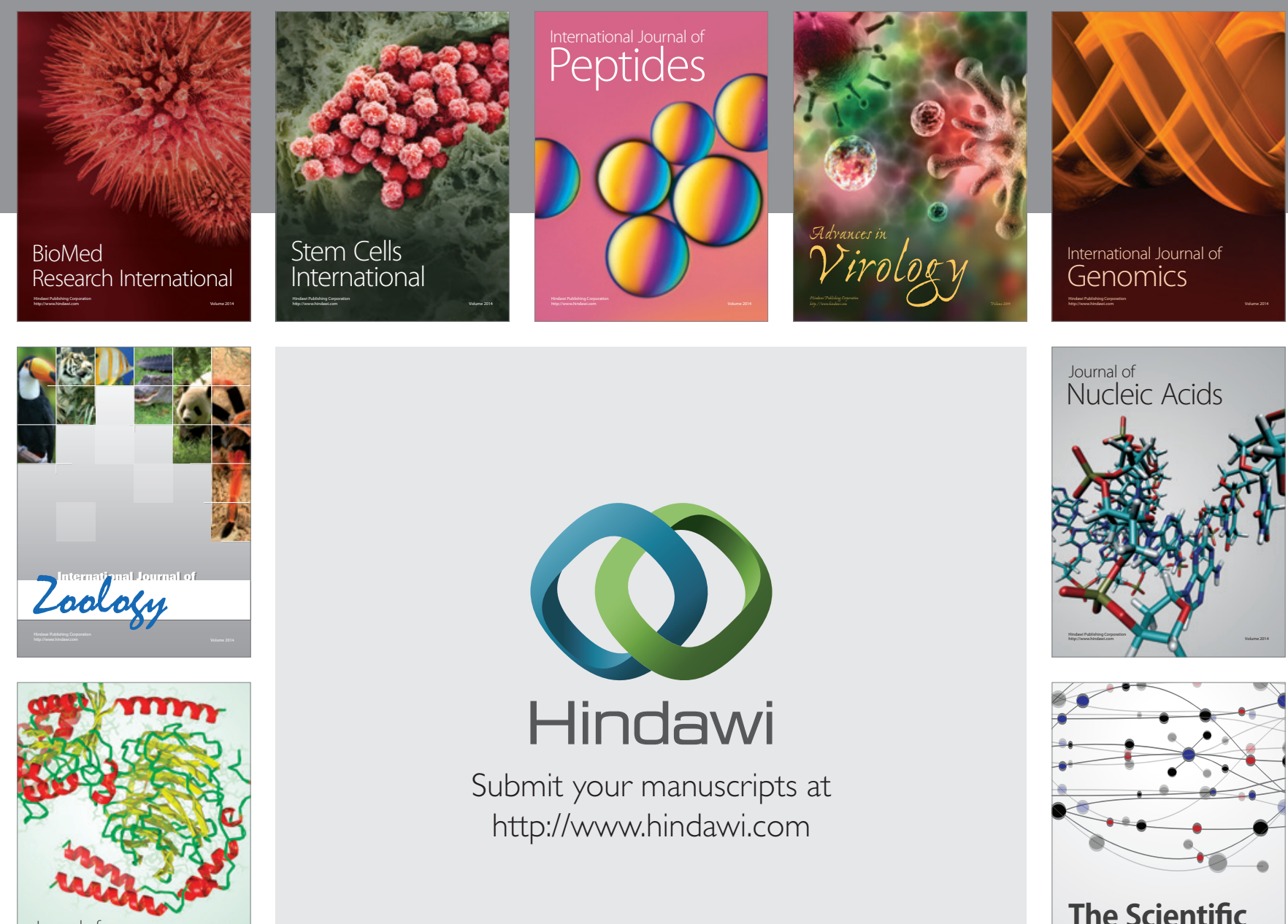

Submit your manuscripts at

http://www.hindawi.com

Journal of
Signal Transduction
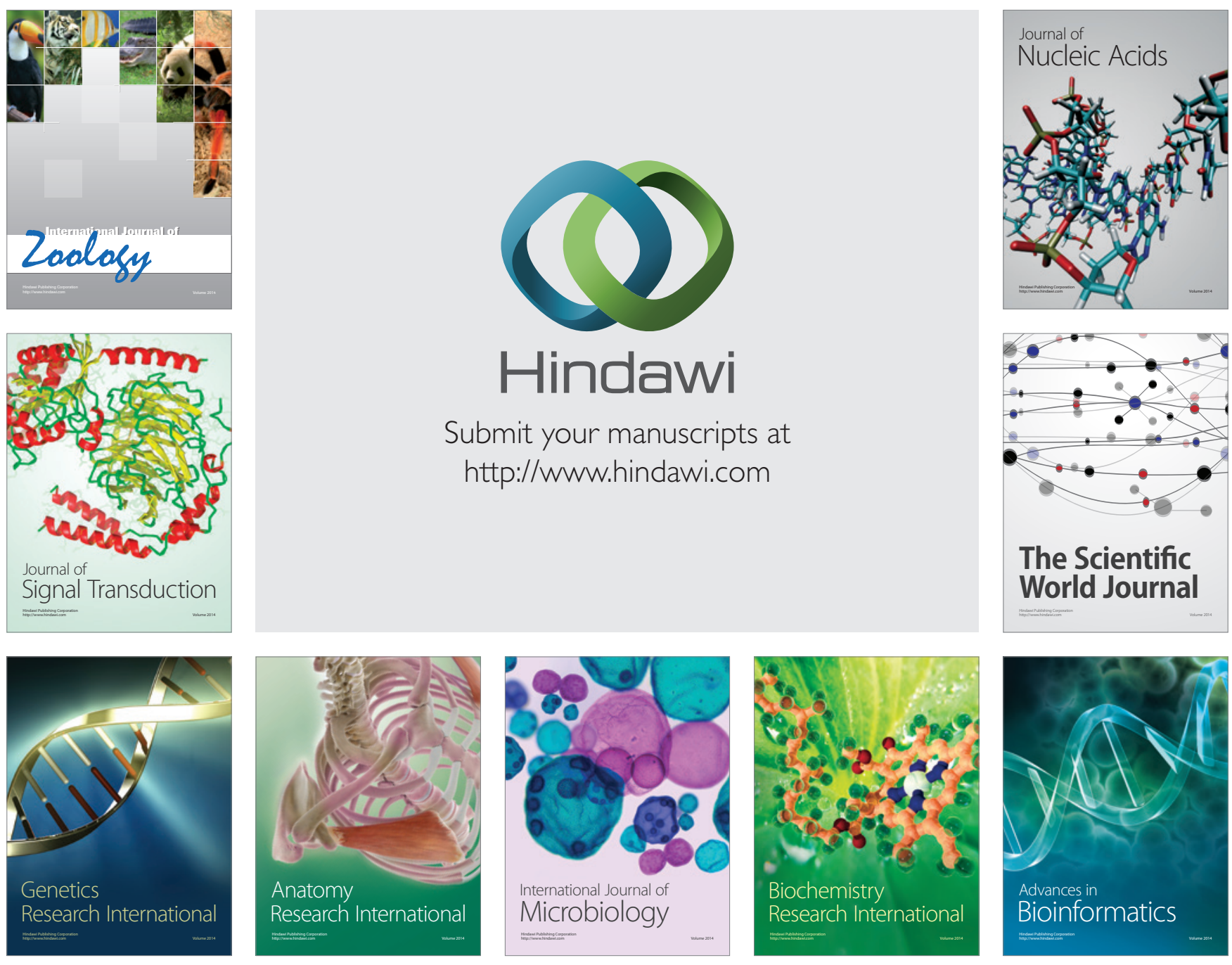

The Scientific World Journal
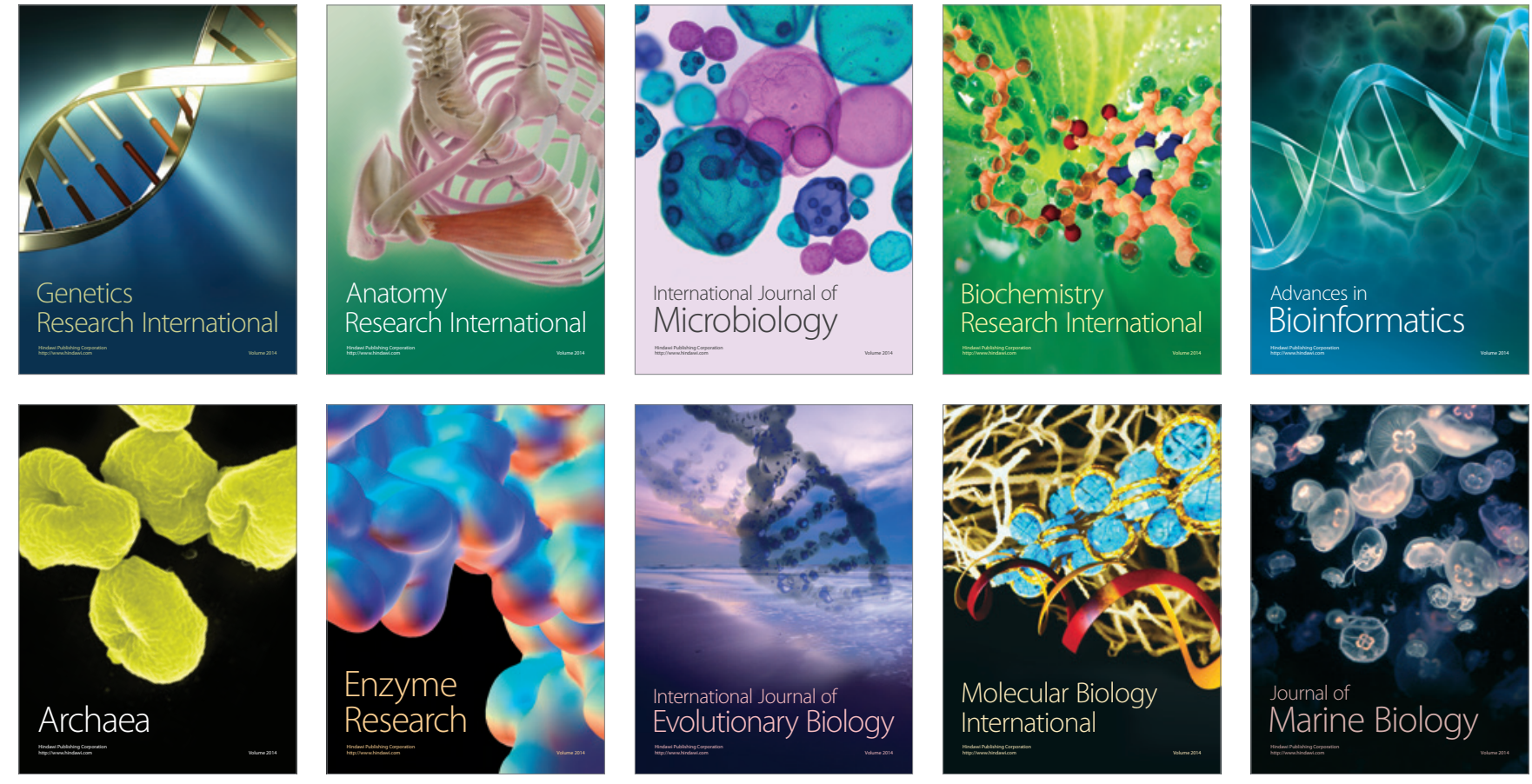